\title{
Experimental Determination of Cooling Rate and its Effect on Microhardness in Submerged Arc Welding of Mild Steel Plate (Grade c-25 as per IS 1570)
}

Rahul Kumar*, Harish K Arya and Saxena RK

Department of Mechanical Engineering, Sant Longowal Institute of Engineering and Technology, Longowal-148106, Punjab, India

\begin{abstract}
An experiment based thermal analysis has been performed to obtain the thermal histories, which can be applied to determine cooling rate of weldment. During fusion welding process it is possible to determine temperature at any point by using thermocouple and from such data it is possible to draw thermal histories for any point of interest, such thermal histories can be utilized to determine cooling rate. The temperature distribution and cooling rate during the welding process have significant effect on the mechanical and metallurgical properties of a weldment. The changes in microstructure, grain growth and hardness in a weldment are very dependent on the temperature distribution and cooling rate. These studies are utilized to investigate the micro-structure and microhardness of the heat affected zone (HAZ) and weldment. In present work, the influence of heat input and cooling rate on microhardness has been investigated. Full factorial design is used to conduct the experiment with three factors and two levels. Eight combinations and two set of heat input are designed with different combinations of SAW welding parameters. Temperature distribution curves and cooling rate have been drawn. The effect of selected welding parameters (Wire feed rate, Open circuit Voltage and welding Speed) on the microhardness have been investigated.
\end{abstract}

Keywords: Cooling rate; Current; Microhardness; Saw welding; Thermocouple; Voltage; Welding speed

\section{Introduction}

With the higher heat input the cooling rate is slower and viceversa. Microstructure and micro-hardness are depend on the cooling rate, faster the cooling rate fine grains are formed and the hardness is increased and by the slower cooling rate coarse grains are formed and hardness is reduced. Submerged Arc Welding (SAW) (Table 1) is used for heat input because of high heat input the other processes [1]. Heat input is increased with increasing wire feeding speed but increasing welding speed decreases the welding heat input. When heat input increases, the cooling rate decreases for weld metal and increases the volume fraction of tempered martensite and coarsening of the microstructure of weld zone. With increasing the wire feeding speed or preheating temperature, brinel hardness of weldment decreases but effect of welding speed on hardness is reversed to other parameters. When welding speed increases the weld hardness also increases [2].

Equation shows the relation between the welding parameters and heat input.

$$
\text { Heat input }=\frac{\mathrm{K} \times \mathrm{V} \times \mathrm{I} \times 60}{\mathrm{~S} \times 1000} \frac{\mathrm{KJ}}{\mathrm{mm}}
$$

Where ' $V$ ' is arc Voltage in Volts, ' $I$ ' is welding current in Ampere, and ' $\mathrm{S}$ ' is welding speed in $\mathrm{mm} / \mathrm{min}$. ' $\mathrm{K}$ ', the thermal efficiency factor for the welding process, The value of $\mathrm{K}=1$ is taken here for Submerged arc welding [3].

\begin{tabular}{|l|c|}
\hline Manufacturer & $\begin{array}{c}\text { M/S Kanubhai Electrical Pvt. } \\
\text { Ltd., Calcutta }\end{array}$ \\
\hline Current range & $60-1200 \mathrm{Amp}$ \\
\hline Maximum welding current at $60 \%$ duty cycle & $1200 \mathrm{Amp}$ \\
\hline Maximum welding current at $100 \%$ duty cycle & $900 \mathrm{Amp}$ \\
\hline Operating voltage & $26-44 \mathrm{~V}$ \\
\hline Electrical supply & 415 \\
\hline
\end{tabular}

Table 1: Specifications of submerged arc welding machine.

\section{Base plate}

Mild steel plates (Table 2) having size $300 \times 75 \times 12 \mathrm{~mm}$ were used in this investigation. The plates were cut into required length with the help of a power hacksaw as shown in Figure 1.

\begin{tabular}{|c|c|c|c|c|c|}
\hline \multicolumn{7}{|c|}{ Composition of Mild Steel plates } \\
\hline Element & Carbon & Manganese & Sulphur & Phosphorus & Ferrous \\
\hline Percentage & 0.280 & 0.533 & 0.030 & 0.037 & rest. \\
\hline \multicolumn{7}{|c}{ Table 2: Material composition. }
\end{tabular}

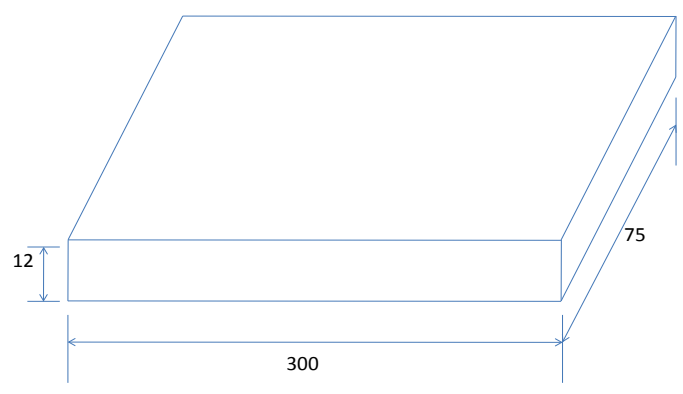

Figure 1: Base plate dimensions $(\mathrm{mm})$

*Corresponding author: Rahul Kumar, Department of Mechanical Engineering, Sant Longowal Institute of Engineering and Technology, Longowal-148106, Punjab, India, Tel: 01672-253123; E-mail: rahulkumar589@gmail.com

Received February 07, 2014; Accepted July 21, 2014; Published August 08, 2014

Citation: Kumar R, Arya HK, Saxena RK (2014) Experimental Determination of Cooling Rate and its Effect on Microhardness in Submerged Arc Welding of Mild Steel Plate (Grade c-25 as per IS 1570). J Material Sci Eng 3: 138 doi:10.4172/2169-0022.1000138

Copyright: (C) 2014 Kumar R, et al. This is an open-access article distributed under the terms of the Creative Commons Attribution License, which permits unrestricted use, distribution, and reproduction in any medium, provided the original author and source are credited. 
Citation: Kumar R, Arya HK, Saxena RK (2014) Experimental Determination of Cooling Rate and its Effect on Microhardness in Submerged Arc Welding of Mild Steel Plate (Grade c-25 as per IS 1570). J Material Sci Eng 3: 138. doi:10.4172/2169-0022.1000138

\section{Electrode wire}

The electrode wire used for the welding was Auto melt Grade-A of $3.15 \mathrm{~mm}$ diameter conforming to AWS SFA 5.17, EL-08 [4].

\section{Flux}

An agglomerate flux and crushed slag was used in this investigation. The specification of flux used for welding is AWS 5.17 OK FLUX 10.71 L, F7AZ-EL 8.

\section{Methodology}

To study the effect of cooling rate on microhardness the following steps were followed.

\section{Preparation of base plate}

- Identifying the process parameters and their limits

- Developing the design matrix

- $\quad$ Conducting the experiments as per the design matrix

- Measurement of temperature during experimentation

- Calculating the cooling rate

- $\quad$ Temperature Measurement

For the investigation the K-type thermocouples were used. Type $\mathrm{K}$ (chromel-alumel) is the most common general purpose thermocouple. It is inexpensive and available in a wide variety of probes. They are available in the $-200^{\circ} \mathrm{C}$ to $+1350^{\circ} \mathrm{C}$ range. The range of thermocouples used for experimentation from $1^{\circ} \mathrm{C}$ to $1200^{\circ} \mathrm{C}$. Each thermocouple was connected to the digital meter for the recoding of temperature at same time interval [5]. Four blind holes (each hole was $6 \mathrm{~mm}$ deep) were produced to the opposite of weld surface in each plate, for the positioning of thermocouples during welding. First hole was made at the center of bead and next holes were $1 \mathrm{~mm}$ apart from its previous hole in perpendicular direction to the bead axis. The dimensions, positioning of holes and actual plate are illustrated in Figures 2 and 3.

Each hole is $5 \mathrm{~mm}$ deep and having $1.5 \mathrm{~mm}$ diameter. The holes were drilled by the vertical pillar drilling machine in the machine shop, SLIET, Longowal. 20 plates were prepared for the experimentation.

\section{Identify the process parameters}

Extensive trial runs were carried out to find out the working range of input welding parameters for producing sound welding. By the trial runs following parameters were selected given in Table 3.

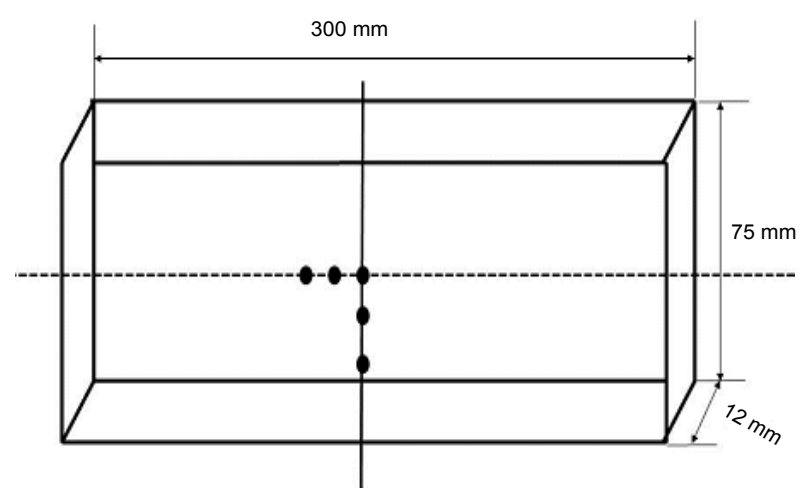

Figure 2: Thermocouple position.

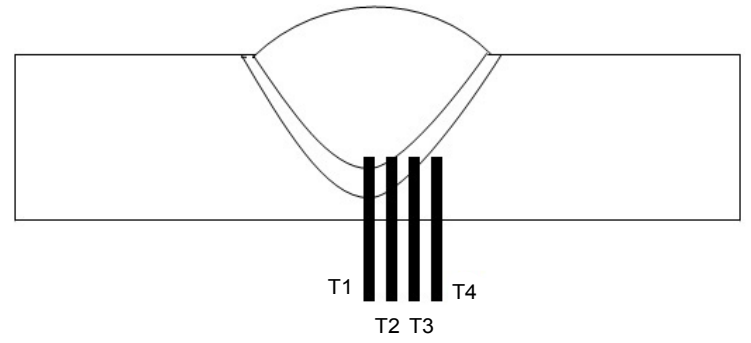

Figure 3: Insertion of thermocouple.

\begin{tabular}{|c|c|c|c|c|c|}
\hline S. No. & Parameters & Units & Symtbols & Low Level (-) & High Level (+) \\
\hline 1 & Wire feed rate & $\mathrm{m} / \mathrm{min}$ & $\mathrm{f}$ & 0.76 & 2.40 \\
\hline 2 & Open Circuit Voltage & Volts & $\mathrm{V}$ & 32 & 42 \\
\hline 3 & Welding Speed & $\mathrm{m} / \mathrm{min}$ & $\mathrm{S}$ & 0.225 & 0.425 \\
\hline
\end{tabular}

Table 3: Process parameters and their levels.

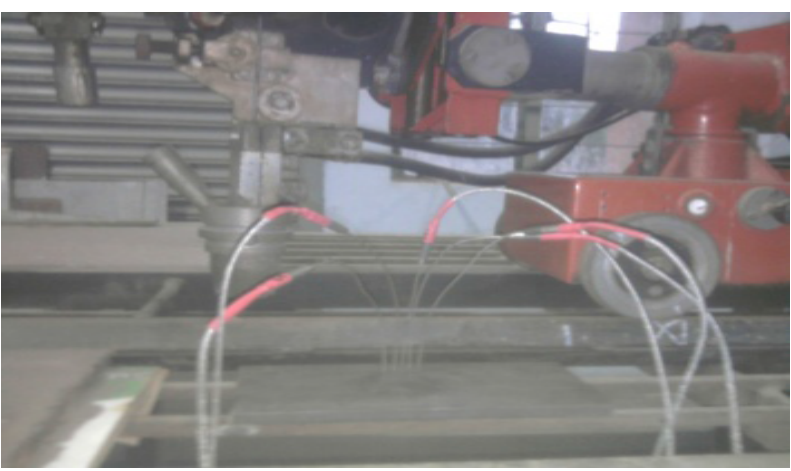

Figure 4: welding setup, base plate and position of thermocouple.

\begin{tabular}{|c|c|c|c|}
\hline S. No. & Current (A) & Voltage (V) & Welding Speed $(\mathbf{m} / \mathbf{m m})$ \\
\hline 1 & - & - & - \\
\hline 2 & + & - & - \\
\hline 3 & - & + & - \\
\hline 4 & + & + & - \\
\hline 5 & - & - & + \\
\hline 6 & + & - & + \\
\hline 7 & - & + & + \\
\hline 8 & + & + & + \\
\hline
\end{tabular}

"+" and "-" shows the High and Low levels respectively.

Table 4: Design matrix.

\section{Preparation of design matrix}

After the selection of welding parameters and their levels on the basis of trials the design matrix was prepared [6]. Table 4 shows the design matrix with different heat input.

Modeling of process parameters and design of experiments have been done with Design Expert software. Full factorial design technique was used for the experimentation. There were three factors and two levels for developing the design matrix, according to the Full Factorial design $\left(2^{\mathrm{n}}\right)$ eight set of heat input are designed with different combinations of SAW welding parameters [7].

\section{Experimentation}

The four thermocouples were positioned in to the holes of base plate 
Citation: Kumar R, Arya HK, Saxena RK (2014) Experimental Determination of Cooling Rate and its Effect on Microhardness in Submerged Arc Welding of Mild Steel Plate (Grade c-25 as per IS 1570). J Material Sci Eng 3: 138. doi:10.4172/2169-0022.1000138

and weld bead is deposited on the opposite surface to the surface where thermocouples are situated. According to the design matrix eight plates were welded using $3.15 \mathrm{~mm}$ diameter conforming to AWS A5.17- 69, EL-08 wire and with the use of fresh flux [8]. Electrode positive reverse polarity was used. A constant potential transformer-rectifier type power source with a current capacity of 1200 amperes at $60 \%$ duty cycle and 900 amperes at $100 \%$ duty cycle, an OCV of 32 to 42 volts was used. The complete set of eight trials was repeated twice for the sake of determining the variance of parameters and variance of adequacy for the model. Figure 4 show the welding setup, base plate and position of thermocouple.

With the help of thermocouple and digital meter the temperature during cooling is recorded at four positions of thermocouple with the interval of 5 seconds. The cross-section view of weld bead with thermocouple is illustrated in Figure 5. The temperature is recorded up to 7 minutes. This recorded temperature helps to draw the thermal histories.

\section{Preparation of test specimen}

After welding, transverse section of the weld beads were cut from the middle portion of the plates as specimens as shown in Figures 4-6. These specimens were prepared by standard metallurgical polishing methods [9]. After applying the 1000 grade of sand paper the micro hardness was carried out in metallurgy lab, SLIET Longowal.

\section{Result and Discussion}

In the present study, the effect of cooling rate on microstructure and microhardnes of mild steel plate has been investigated. The properties of steel welds are affected by their cooling rates in the $800^{\circ} \mathrm{C}$ to $500^{\circ} \mathrm{C}$ range where the phase transformations important for the evolution of final weld microstructure occur. The effect of cooling rate is not limited to solid state transformations. Cooling rate of weldment is depends on the heat input by the welding arc to the weldment. Heat input is controlled by the three variables wire feed rate, open circuit Voltage, welding speed. With the higher heat input the cooling rate is slower and vice-versa. The effect of cooling rate on microhardness was investigated.

\section{Cooling rate}

Cooling rate is calculated from $800^{\circ} \mathrm{C}$ to $500^{\circ} \mathrm{C}$, because this temperature range is useful to phase transformation. It is observed that when heat input is increased the cooling rate of weldment is reduced. Cooling rate is calculated by the following equation. Table 5 shows the calculated heat input and cooling rate. Heat input is calculated from welding parameters and cooling rate is calculated from thermal histories.

Cooling rate $=\quad$ Temp range from $800^{\circ} \mathrm{C}$ to $500^{\circ} \mathrm{C}$

$$
\text { Time taken from } 800^{\circ} \mathrm{C} \text { to } 500^{\circ} \mathrm{C} \text { during cooling }
$$

Table 5 illustrates the relation between the heat input and cooling rate of weldment. It is observed that the increasing in heat input from

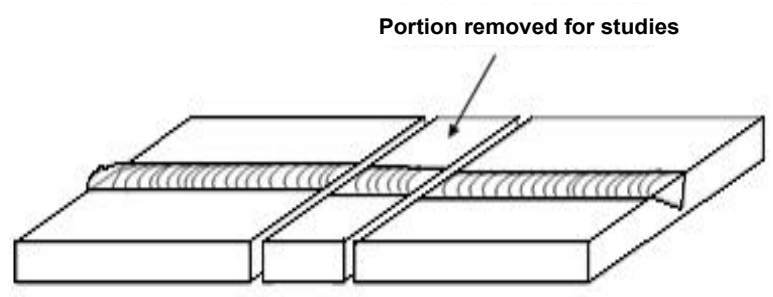

Figure 5: Removal of specimen from the work piece.

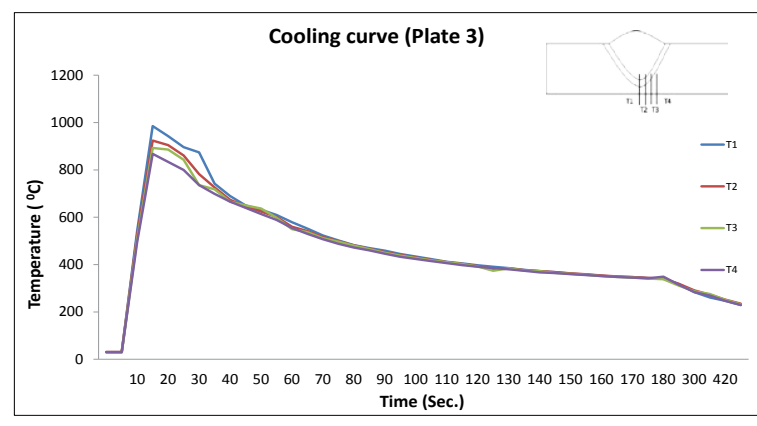

(a)

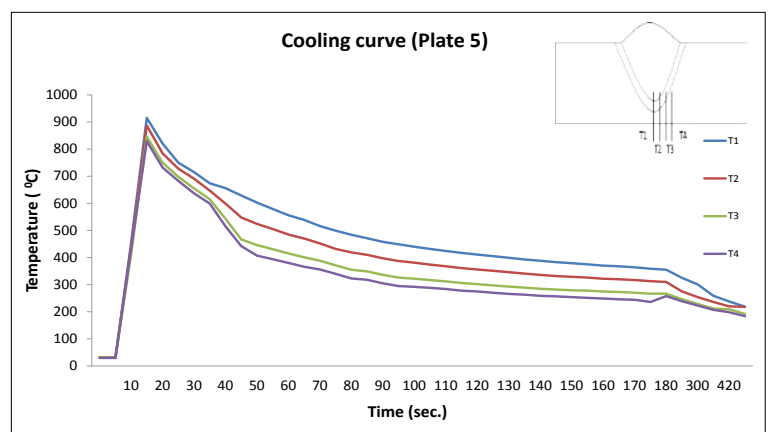

(b)

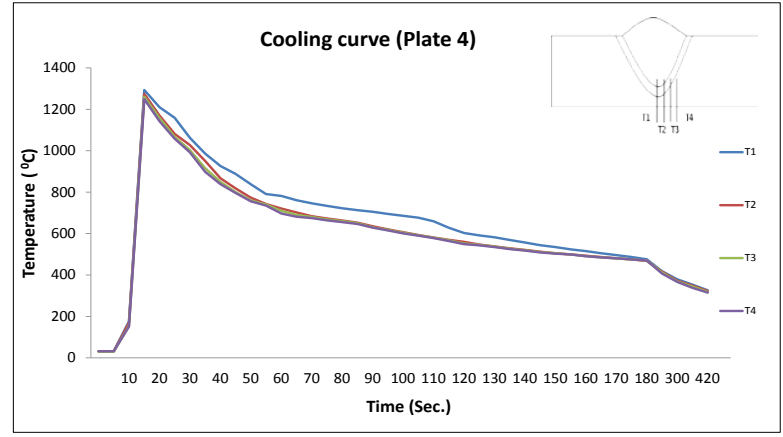

(c)

Figure 6: Cooling Curve at (a) Medium (b) High and (c) Low Cooling Rate.

\begin{tabular}{|c|c|c|}
\hline plate no. & HI in J/m & CR (800-500) \\
\hline 1 & 1.86 & 8.42 \\
\hline 2 & 2.94 & 7.31 \\
\hline 3 & 2.76 & 8.92 \\
\hline 4 & 4.15 & 2.65 \\
\hline 5 & 0.80 & 9.83 \\
\hline 6 & 1.40 & 4.72 \\
\hline 7 & 1.34 & 7.13 \\
\hline 8 & 2.01 & 5.64 \\
\hline
\end{tabular}

$0.80 \mathrm{~J} / \mathrm{m}$ to $4.15 \mathrm{~J} / \mathrm{m}$ the cooling rate is reduced from $9.83^{\circ} \mathrm{C} / \mathrm{sec}$ to $2.65^{\circ} \mathrm{C} / \mathrm{sec}$. so with the reduction in heat input the cooling rate is increased.

\section{Temperature histories}

During welding, temperature is measured as a function of time, by thermocouple for different points. These readings of temperature are 
Citation: Kumar R, Arya HK, Saxena RK (2014) Experimental Determination of Cooling Rate and its Effect on Microhardness in Submerged Arc Welding of Mild Steel Plate (Grade c-25 as per IS 1570). J Material Sci Eng 3: 138. doi:10.4172/2169-0022.1000138

\begin{tabular}{|c|c|c|c|}
\hline plate no. & CR (800-500) & Av. Hardness Weld & Av. Hardness HAZ \\
\hline 1 & 8.42 & 208 & 228 \\
\hline 2 & 7.31 & 205 & 225 \\
\hline 3 & 8.92 & 210 & 230 \\
\hline 4 & 2.65 & 165 & 177 \\
\hline 5 & 9.83 & 227 & 237 \\
\hline 6 & 4.72 & 175 & 186 \\
\hline 7 & 7.13 & 182 & 215 \\
\hline 8 & 5.64 & 180 & 207 \\
\hline
\end{tabular}

Table 6: Calculated cooling rate and microhardness of weld as well as HAZ.

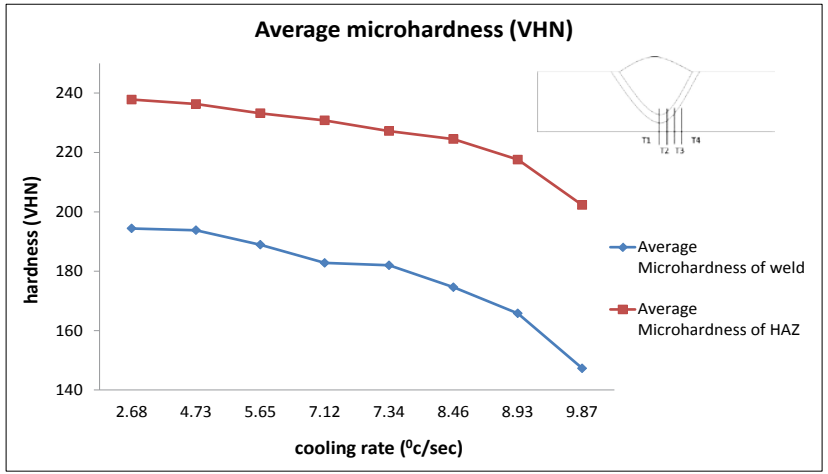

Figure 7: Relation Microhardness and cooling rate.

useful to draw temperature histories. Thermal histories play important role for finding the cooling rate of weldment for different ranges. Figure 6 shows the temperature history of weldment [10], welded at Low medium and high cooling rates.

\section{Microhardness}

\section{Average microhardness of all weldment}

Table 6 and Figure 7 illustrate the average microhardness of all eight combination of cooling rate. It is observed that when cooling rate is increased the average microhardness of weldment reduced and hardness of HAZ is higher as compared to weld.

\section{Conclusion}

The following conclusions may obtain from the experiments:

- The process parameters are directly affect the cooling rate, with the increase of wire feed rate, open circuit voltage and decreasing of welding Speed the cooling rate is decreased and with the decreasing of wire feed rate, open circuit voltage and increasing of welding speed the cooling rate become fast.

- The grains forms with higher cooling rate are much finer as compare with low cooling rate.

- Low heat input and high cooling rate result in fine grain structure and cause the higher hardness.

- With increase in heat input from low $(0.80 \mathrm{~J} / \mathrm{m})$ to high $(4.15$ $\mathrm{J} / \mathrm{m})$ The cooling rate reduced from $\left(9.83^{\circ} \mathrm{C} / \mathrm{sec}\right.$ to $\left.2.65^{\circ} \mathrm{C} / \mathrm{sec}\right)$ due to this slower cooling rate and increase in heat input hence this grain coarsening directly affects the microhardness of HAZ and weld zone which reduced by $27.3 \%$ in weld zone and $25.3 \%$ in HAZ.

\section{References}

1. Kou S (2003) Welding Metallargy. (2nd Edn.), John Wiley \& Sons, Inc., New Jersey, USA.

2. Challenger KD, Brucker RB, Elger WM, Sorek MJ (1984) MicrostructureThermal History Correlations for HY-130 Thick Section Weldments. Welding Journal Research Supplement: 254-261.

3. Honarbakhsh-Raouf A, Ghazvinloo HR (2010) Influence of Wire Feeding Speed, Welding Speed and Preheating Temperature on Hardness and Microstructure of Weld in RQT 701-british Steel Produced by FCAW. Indian Journal of Science \& Technology 3: 588-591.

4. Datta S, Sundar M, Bandyopadhyay A, Nandi G, Pal PK, et al. (2005) Effect of Electrode Stick out on Quality and Performance of Submerged Arc WeldmentExperimental and Statistical Analyses. Proceedings of the International Conference on Mechanical Engineering, Dhaka, Bangladesh.

5. Nadkarni SV (1988) Modern Arc Welding Process. (4th Edn.), Oxford \& IBH publishing Co. Pvt. Ltd, New Delhi, India.

6. Ibrahim K (2007) Welding Science and Technology. New Age International, India.

7. Parmar RS (2010) Welding Engineering and Technology. Khanna Publishers, New Delhi, India.

8. Attarha MJ, Sattari-Far I (2011) Study on welding temperature distribution in thin welded plates through experimental measurements and finite element simulation. Journal of Materials Processing Technology 211: 688-694.

9. Douglas CM (2008) Design and Analysis of Experiments. John Wiley \& Sons, Inc., USA.

10. Gunaraj V, Murugan N (1999) Prediction and comparison of the area of the heat-affected zone for the bead-on-plate and bead-on-joint in submerged arc welding of pipes. Journal of Materials Processing Technology 95: 246-261. 